\title{
Numerical investigation of PLIF gas seeding for hypersonic boundary layer flows
}

\author{
C.T. Johansen ${ }^{1}$ \\ University of Calgary, Calgary, $A B, T 2 N 1 N 4$ \\ P.M. Danehy ${ }^{2}$ \\ NASA Langley Research Center, Hampton VA, 23681-2199
}

\begin{abstract}
Numerical simulations of gas-seeding strategies required for planar laser-induced fluorescence (PLIF) in a Mach 10 air flow were performed. The work was performed to understand and quantify adverse effects associated with gas seeding and to compare different flow rates and different types of seed gas. The gas was injected through a slot near the leading edge of a flat plate wedge model used in NASA Langley Research Center's 31Inch Mach 10 Air Tunnel facility. Nitric oxide, krypton, and iodine gases were simulated at various injection rates. Simulation results showing the deflection of the velocity field for each of the cases are presented. Streamwise distributions of velocity and concentration boundary layer thicknesses as well as vertical distributions of velocity, temperature, and mass distributions are presented for each of the cases. Relative merits of the different seeding strategies are discussed.
\end{abstract}

\section{Introduction}

$\mathrm{T}$ HE injection and dispersion of a seed gas upstream of a fluid dynamic phenomenon is a common strategy when performing non-intrusive measurements. The use of a seed gas as a fluid tracer is useful in flow visualization applications since the seeded gas convects through the velocity field and marks fluid flow structures. Depending on the application, either uniform or localized seeding is required. In studies using planar laser-induced fluorescence (PLIF), for example, uniform seeding is preferred where quantitative measurements like temperature or velocity are required, while local seeding may be more advantageous when flow visualization is required, particularly in applications involving blowing. Although gas seeding can be avoided in some applications where the fluorescence species forms naturally in the flow, such as in combustion flows (hydroxyl radical, $\mathrm{OH}$ ) or in high enthalpy wind tunnels (nitric oxide, NO), it is often unavoidable. Examples of when localized seeding is required for PLIF flow visualization include the study of fuel-air mixing for supersonic combustion ramjet (SCRAMJET) engines ${ }^{1}$ and the study of reaction control system jet interactions with hypersonic crossflows associated spacecraft entry vehicles. ${ }^{2,3}$

The strategy of seeding tracer gas into a flow to enable PLIF measurements has recently been used to study laminar-to-turbulent transition in hypersonic boundary layers. ${ }^{4-9}$ NASA's interest in this fluid dynamic problem is mainly motivated to further understand the increase in the surface heating that accompany the transition to turbulence during the atmospheric entry of spacecraft vehicles. ${ }^{10}$ Figure 1 shows a sample result from an NO PLIF experiment where a 20 degree wedge is positioned in a hypersonic flow. ${ }^{11}$ The wedge has a $0.81-\mathrm{mm}$ thick, $11-\mathrm{mm}$ wide slot located approximately $29.4 \mathrm{~mm}$ downstream of the leading edge where NO gas is injected. In this particular test, a Boundary Layer Transition Detailed Test Objective (BLT DTO) shaped-trip was used to cause the flow to transition to turbulence. The laser sheet was oriented parallel to the model surface giving a plan-view visualization of the flow as it passes over the trip. The images were processed using the Virtual Diagnostics Interface (ViDI) method, which assists in the visualization of three-dimensional flow structures. The flow is smooth and laminar as it exits the slot and approaches the trip. Thin streamwise streaks are visible downstream of the trip, while crossflow instabilities lead to three-dimensional structures further downstream. Eventually the flow breaks down into smaller, more irregular structures that eventually lead to a transition to turbulent flow. Since NO is seeded downstream of the plate's leading edge, visualization is only possible within the boundary layer, where the seed gas

\footnotetext{
${ }^{1}$ Assistant Professor, Mechanical and Manufacturing Engineering, Member AIAA.

${ }^{2}$ Research Scientist, Advanced Sensing and Optical Measurement Branch, MS 493. AIAA Associate Fellow.
} 
has been transported. The dark band downstream of the leading edge of the protuberance in the image is mainly from unseeded freestream gas that convects down towards the model surface by a streamwise vortex. Density variations within the seeded gas also cause the signal to vary.

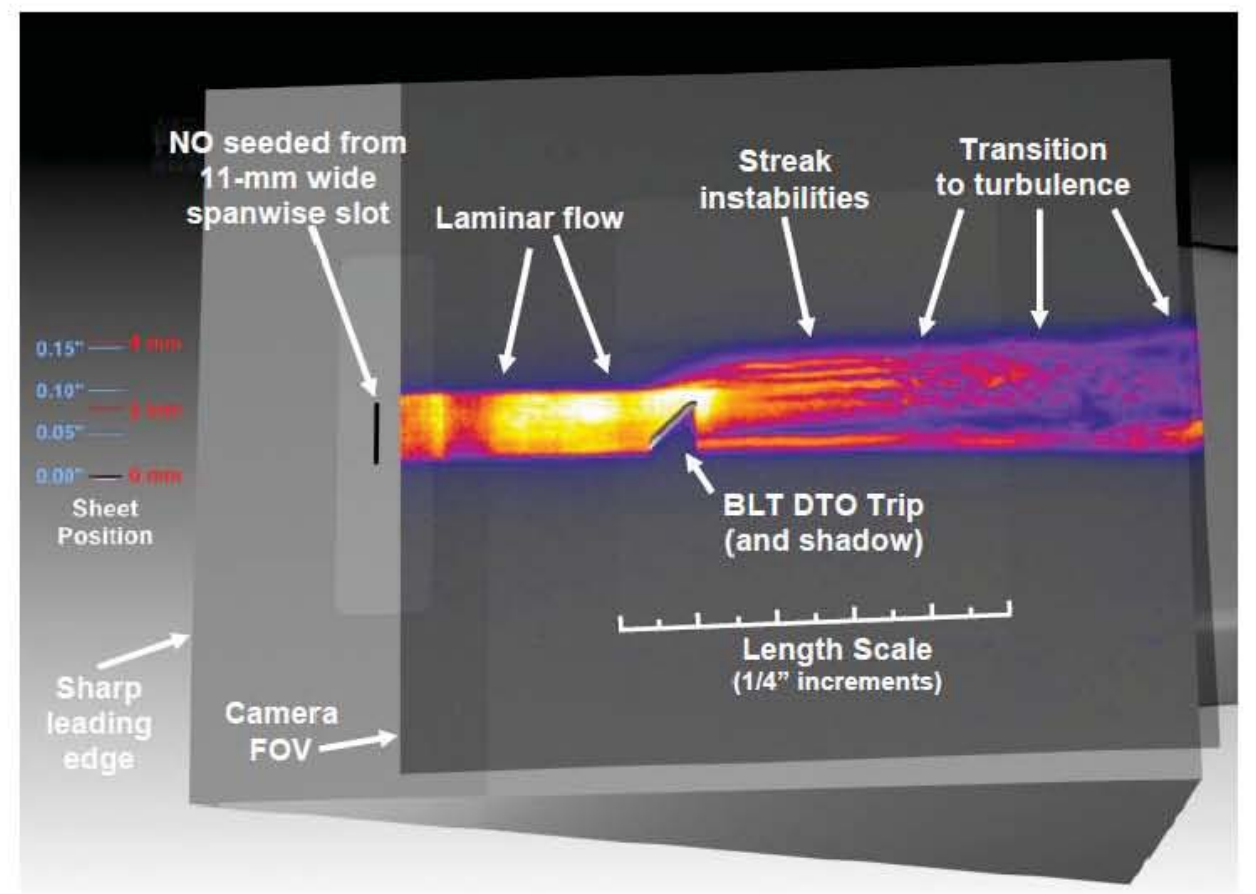

Figure 1: ViDI rendering of a typical $10 \mathrm{~Hz}$ NO PLIF image of Space Shuttle Orbiter BLT DTO shaped trip in Mach 10 flow. Reproduced from Ref. 11.

Injecting a foreign gas into a flow has several requirements and limitations. First, when used with a non-intrusive technique, it is important that the seeded gas does not adversely affect any important features of the flow. In addition to unwanted aerodynamic effects, local thermodynamic properties near the injected gas can be affected, which can alter dimensionless parameters important in the flow. For example, changes in the local specific-heat ratio, thermal conductivity, or viscosity could result in local changes in the Mach number, Prandtl number, or Reynolds number, respectively. If the seeded gas is a reactive species, then there is also a concern that the heat release from reactions might also distort the flow field.

Gas seeding near the model or from the model can present challenges but often can be incorporated seamlessly into a test. If gas injection is being used anyway, for example, then gas seeding through the jets does not perturb the flow field if the seed gas is non-reacting and does not significantly change the thermodynamic properties of the jet. Seeding of nitric oxide into the reaction control system (RCS) jets of the Orion Crew Exploration Vehicle is an example of this type of gas seeding strategy. ${ }^{2,3}$ Another example of intentional blowing is the use of jets for active control of hypersonic boundary layers. ${ }^{12}$ If gaseous injection is not being studied then injection through a port normal to the flow on the model surface can be used. In this case, if the ratio of the injected gas momentum to crossflow momentum is too large, then the injected gas will severely augment the crossflow and perhaps become a source of instability.

For boundary layer transition experiments, a tradeoff exists between perturbing the flow and depositing high enough concentrations of fluorescence species into the region of interest. Measurements far from the wall are desired because transition to turbulence begins near the edge of the boundary layer in hypersonic flows. ${ }^{13}$ The seed material is transported away from the wall both by advection (if the injected gas momentum is relatively high) and by diffusion. Therefore, the rate of diffusion of the seed gas into the crossflow gas is important since it affects concentration levels downstream of the injection location in applications where perturbing the flow is undesirable. An analytic expression describing the growth of a concentration boundary layer relative to the growth of an incompressible velocity boundary layer on a two-cimensional flat plate is useful in understanding this process. ${ }^{14}$ The ratio of the concentration to velocity boundary layer thickness, $\delta_{\mathrm{e}} / \delta$, is defined as: 


$$
\frac{\delta_{c}}{\delta}=\left(\frac{13}{14}\right)^{1 / 3} S c^{-1 / 3}\left(1-\left(\frac{x_{0}}{x}\right)^{3 / 4}\right)^{1 / 3}
$$

where $x$ and $x_{0}$ are the distance from the plate leading edge and gas seeding location, respectively. These parameters are illustrated in Fig. 2. In this expression, it is assumed that the velocity of the seeded gas is negligible compared to freestream flow. In addition, it is assumed that the flow is laminar, incompressible, and steady. $S c$ is the Schmidt number defined as:

$$
S c=\frac{\mu}{\rho D}
$$

where $\mu, \rho$, and $D$ are the dynamic viscosity, gas density, and diffusion coefficient, respectively. The formula to compute the diffusion coefficient is defined below in Eqn. 3. Seeded gas with relatively low Schmidt numbers experience fast rates of mass diffusion, allowing the concentration layer to penetrate and extend past the velocity boundary layer. In contrast, seeded gas with a large Schmidt number will remain concentrated closer to the plate surface. The position of the injection location relative to the plate leading edge $\left(x_{0}\right)$ is also important since the velocity boundary layer has a finite thickness at the injection location. Although Eqn. 1 is based on incompressible flow assumptions and constant distribution of Schmidt number, the expression is still useful for illustrating trends on the diffusion of different seed gases.

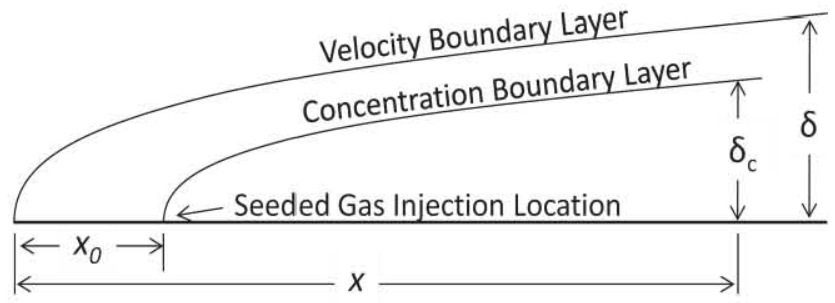

Figure 2: Schematic of growth of the velocity and concentration boundary layers on a flat plate. Adapted from Ref. 14.

The objectives of this study are to 1) identify and further understand adverse fluid dynamic effects of seeding various pure gases from a slot, 2) determine how far from the wall different seed gases penetrate and 3 ) compare the relative merits of the different seed gases in terms of perturbations to the flow and the spatial range of coverage provided. In this work it is assumed that the purpose of the gas seeding is to allow qualitative and quantitative PLIF measurements to be performed. Using computational fluid dynamics (CFD), three different seed gases: nitric oxide (NO), krypton ( $\mathrm{Kr})$, and iodine $\left(\mathrm{I}_{2}\right)$ have been simulated. These seed gases have been selected as they are typically used for flow visualization or quantitative measurement purposes with the PLIF technique, for example in Ref. 15 for $\mathrm{Kr}$ and Refs. 16, 17 for $\mathrm{I}_{2}$. Each of the seeded gases needs adequate gas handling equipment to ensure the safety of human operators near the wind tunnel apparatus. $\mathrm{NO}$ and $\mathrm{I}_{2}$ are toxic if inhaled at low concentrations, though $\mathrm{NO}$ is relatively more toxic than $\mathrm{I}_{2} ;{ }^{18} \mathrm{NO}$ requires special gas handling equipment with increased safety concerns. In comparison, $\mathrm{Kr}$ is a non-toxic asphyxiant, easing the restrictions required for gas handling compared to $\mathrm{NO}$ and $\mathrm{I}_{2}$. The molecular weights of $\mathrm{NO}, \mathrm{Kr}$, and $\mathrm{I}_{2}$ are 30,84 , and $254 \mathrm{~g} / \mathrm{mol}$, respectively. With artificial seeding, it is preferable to match the molecular weight of the freestream gas $\left(\mathrm{MW}_{\text {air }} \sim 29 \mathrm{~g} / \mathrm{mol}\right)$. The thermal conductivity, molecular viscosity, and mass diffusivity are all dependent on the molecular weight of the seeded gas. Depending on the pressure, NO can quickly react with oxygen at the low temperatures that typically occur in hypersonic ground facilities. In contrast, $\mathrm{Kr}$ and $\mathrm{I}_{2}$ do not react with air. The effects of chemical reactions on the flow, however, are not considered in this study. Instead, special attention is given to the rates of gas diffusion and the growth of the concentration boundary layer relative to the velocity boundary layer for each respective gas. Several seeding flow rates have been simulated to observe the levels of deformation of the existing velocity boundary layer and to understand any adverse effects that seeding has on the PLIF measurements. 


\section{Numerical Setup}

Steady, two-dimensional, laminar numerical simulations of gas seeding were performed using the commercial computational CFD software, ANSYS® Fluent v. 6.3. The density-based solver was used, which simultaneously solves the compressible continuity, momentum, energy, and species transport equations as a coupled set. Since the PLIF experiments indicated that the flow was steady and laminar, a two-dimensional computational domain was considered to be adequate to capture the important physics of the flow. An Euler implicit time discretization scheme with Newton-type linearization for fluxes was used. ${ }^{19}$ The Roe Flux-Difference Splitting scheme was used for convective fluxes with second order accuracy. ${ }^{20}$

The geometry and flow conditions specified in the simulations are based on the geometry of tests performed in the NASA Langley Research Center's 31-Inch Mach 10 Air Tunnel facility. ${ }^{11}$ A schematic of the computational domain relative to the 20 degree full-angle wedge model is shown in Fig. 3. During the tests, the sting can be rotated to give different angles of attack, specified as the "plate angle", $\theta_{\text {plate }}$, which is defined as the angle of the plate with respect to the oncoming freestream flow. The freestream conditions describing the simulations performed are a freestream static pressure of $P_{f s}=68 \mathrm{~Pa}$, freestream static temperature of $T_{f s}=52 \mathrm{~K}$, and a freestream Mach number of $\mathrm{Ma}=9.7$. The sting was rotated so that the plate angle relative to the freestream was $\theta_{\text {plate }}=5 \mathrm{deg}$. At this plate angle, an oblique shock wave forms at the plate's leading edge. The theoretical shock angle relative to the plate surface (computed for gamma of 1.4 and assuming a sharp leading edge with no boundary layer) is approximately $\theta_{\text {shock }}=4.5 \mathrm{deg}$. The theoretical post-shock conditions behind the oblique shock wave are $P_{2}=201 \mathrm{~Pa}, T_{2}=74 \mathrm{~K}$, and $\mathrm{Ma}_{2}=8.1$. At a streamwise location relative to the leading edge of $x=74.8 \mathrm{~mm}$, corresponding to the BLT DTO trip location shown in Fig. 1 , the post shock conditions were $P_{2}=255 \mathrm{~Pa}, T_{2}=82.5 \mathrm{~K}$, and $\mathrm{Ma}_{2}=7.6$. The injection seeding slot is $0.81 \mathrm{~mm}$ thick and is located $29.4 \mathrm{~mm}$ downstream of the leading edge. The rectangular computational domain relative to the plate surface is shown in Fig. 3 as a red dashed line. The upstream boundary of the computational domain coincides with the plate leading edge and extends past the downstream end of the plate surface. The expansion associated with the junction of the sting and rear wedge model was not simulated. As the post-shock conditions are supersonic, the location of the rear boundary is not expected to alter the results.

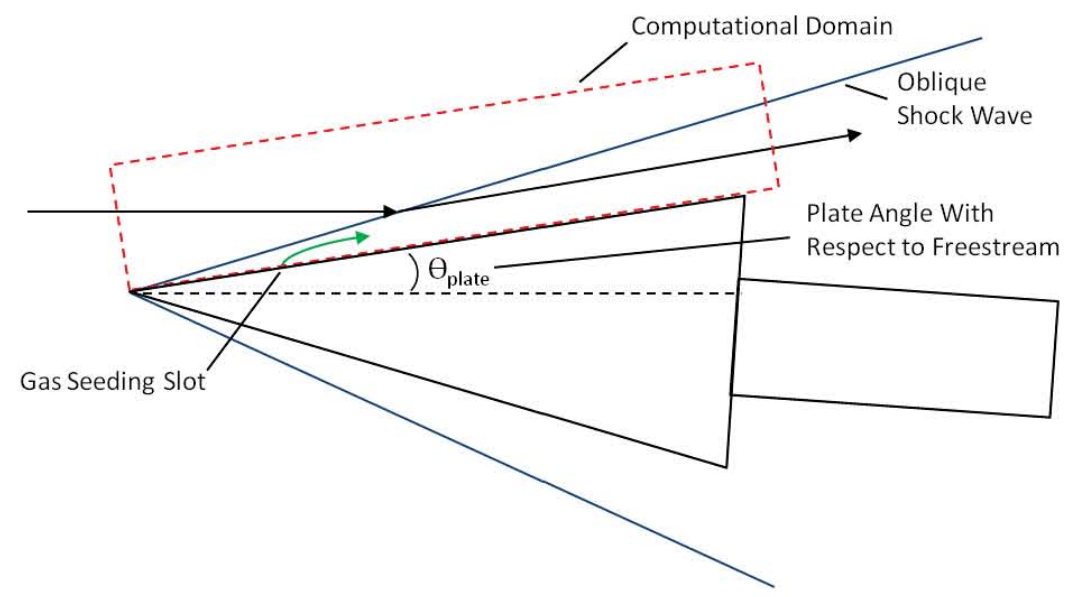

Figure 3: Computational domain relative to experimental setup. This is a side view of the wedge shown in Fig. 1 without a trip present.

Figure 4 shows a schematic of the computational domain along with the relevant boundary conditions. The domain has been rotated 5 degrees relative to Fig. 3 to simplify the grid generation process. Since the domain is rotated relative to the freestream gas, both the upstream and top boundaries are specified as mass inflow boundaries with -5 degree orientation of the inflow velocity vector. As a result, the oblique shock wave that forms in the experiment is simulated, forming at the leading edge near the bottom, upstream edge of the domain. At the upstream inflow boundary, the mass flux is $\rho V=6.39\left(\mathrm{~kg} \cdot \mathrm{m}^{-2} \cdot \mathrm{s}^{-1}\right)$. At the top inflow boundary, the mass flux is $\rho V=0.56$ $\left(\mathrm{kg} \cdot \mathrm{m}^{-2} \cdot \mathrm{s}^{-1}\right)$. At both inflow boundaries the static pressure and total temperature are $P_{\text {static }}=68.4 \mathrm{~Pa}$ and $T_{\text {total }}=1023$ $\mathrm{K}$, respectively. Oxygen and nitrogen species mass fractions equivalent to an air mixture are specified at the inflow boundaries. Chemistry is frozen. The bottom surface is a no-slip, isothermal wall boundary maintained at $314 \mathrm{~K}$, which is consistent with a wall temperature measured with a thermocouple during the experiment. The jet inflow, 
located $29.4 \mathrm{~mm}$ downstream of the upstream inflow boundary is also specified with a mass flux, static pressure, and total temperature. The respective gas species are specified at the jet inflow boundary. These quantities varied based on the gas seeding species and flow rate. Finally an outflow boundary was specified at the downstream side of the domain.

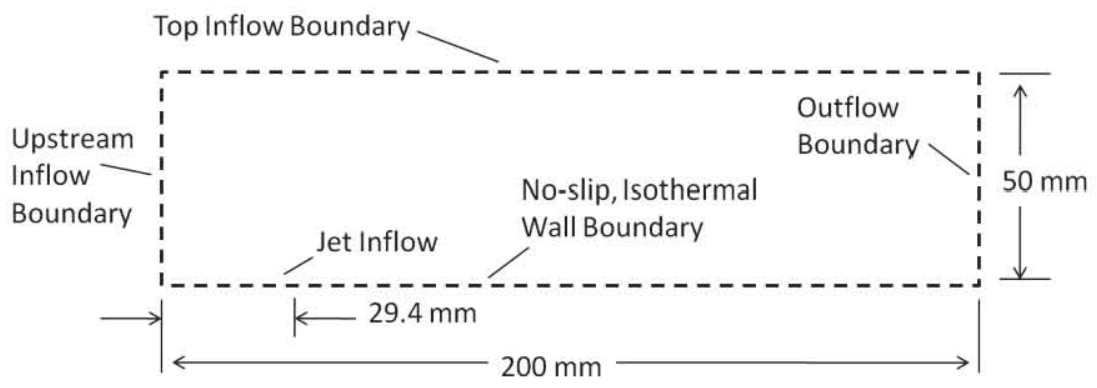

Figure 4: Computational domain and boundary conditions

The thermodynamic properties of the mixture are treated as mass-weighted averages of the individual species' properties. The specific heat, dynamic viscosity, thermal conductivity, and mass diffusivity of each species are specified in Fluent as user defined functions. The specific heat values for $\mathrm{O}_{2}$ and $\mathrm{N}_{2}$ are based on the work of Hollis. ${ }^{21}$ Specific heats for NO, $\mathrm{I}_{2}$, and $\mathrm{Kr}$ are based on the NIST-JANAF tables. ${ }^{22}$ The dynamic viscosity of each species is based on the Chapman-Cowling relationship specified in the work by Hollis. ${ }^{21}$ The collisional cross sections, $\sigma$, for each species are taken from tabulated values produced by Svehla. ${ }^{23}$ The thermal conductivity is based on the modified Euken correction equation taken from the work of Hollis. ${ }^{21}$ The mass diffusivity is based on Fluent's multi-component diffusion model based on kinetic theory. The model computes individual diffusion coefficients, $D_{i j}$, based on the Chapman-Enskog equation ${ }^{24,25}$, which is defined as:

$$
D_{i j}=0.0188 \frac{\left(T^{3}\left(1 / \mathrm{MW}_{i}+1 / \mathrm{MW}_{j}\right)\right)^{1 / 2}}{P_{\mathrm{abs}} \sigma_{i j}^{2} \Omega^{(1.1)^{*}}}
$$

where $P_{\text {abs }}$ and $\Omega^{(1.1)^{*}}$ are the absolute pressure and the diffusion collision integral, respectively. Empirical equations for the diffusion collision integral can be found in the literature. ${ }^{25}$ Note that the diffusion coefficient is dependent on both the individual species molecular weight $\left(\mathrm{MW}_{i}\right)$ and the molecular weight of the surrounding gas $\left(\mathrm{MW}_{j}\right)$.

Figure 5 shows the computational grid near the leading edge and the jet inflow boundary. The base grid concentrates the nodes near the leading edge in both the streamwise and vertical directions, with a resolution of approximately 20 nodes $/ \mathrm{mm}$. Dynamic mesh refinement is used near the wall surface to ensure that the wall $y+$ is less than unity along the entire wall surface. Approximately 16 nodes of the base mesh are distributed across the jet diameter. Near the wall surface, the number of nodes across the jet surface increases to approximately 128 . In the entire computational domain, there are approximately 417,000 nodes. A grid sensitivity analysis showed that an increase in grid size to 1.6 million nodes had no effect on distributions of velocity, mass, or temperature.

a)

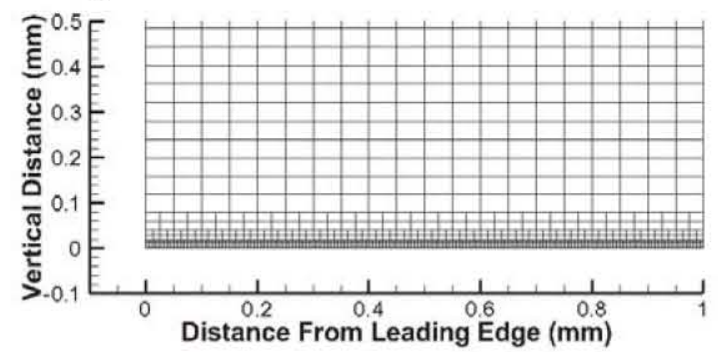

b)

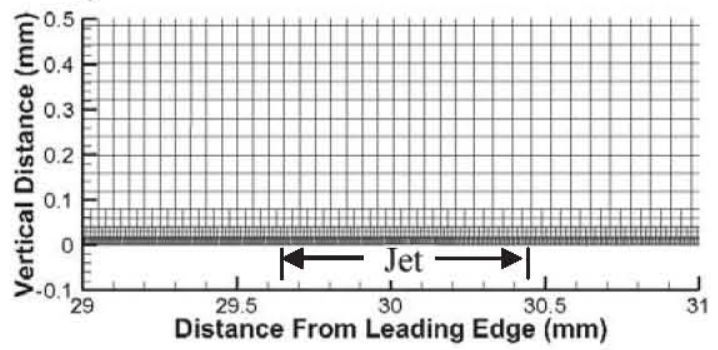

Figure 5: Computational grid near leading edge (a) and at gas seeding location (b). 


\section{Results}

The simulation results of boundary layer flow with only diffusive gas seeding are presented in the first section. The overall flow field is described and the results are compared to theory. In the second section, the effects of jet-incross flow interaction on the velocity profile are presented.

\section{A. Boundary Layer Flow with Diffusive Gas Seeding}

Figure 6 shows distributions of pressure, temperature, and NO species mass fraction from a simulation of flow over the flat plate with diffusive gas seeding of NO. The jet inflow was specified as a no-slip wall boundary with a diffusion flux of the NO. The setup is equivalent to the simulation of a jet with negligible mass flow rate. Only trace levels of the NO are able to diffuse into the velocity boundary layer. Simulations were also performed with the jet boundary specified as a no-slip wall boundary without a diffusive flux. The predictions of velocity, pressure, and temperature were unaffected by the diffusive gas seeding. Stream traces are overlaid onto the respective contour maps. From the pressure and temperature fields the location of the oblique shock wave is visible. The location of the oblique shock coincides with the redirection of the stream traces parallel to the plate surface. Inclusion of the oblique shock wave in the simulation was preferred over using post-shock conditions for the inflow boundary condition to improve overall accuracy. In addition, using post-shock conditions would not properly include leading edge effects. Leading edge effects, which are included in the simulation, cause a large pressure rise at the near wall region of the inflow boundary as the boundary layer begins to form. Since there is no jet velocity, the mass fraction levels of NO are very low, the influence of which are undetectable from the pressure and temperature contour maps. Although low in concentration, the gas is able to diffuse several millimeters away from the surface after $100 \mathrm{~mm}$ downstream of the leading edge. 
a)

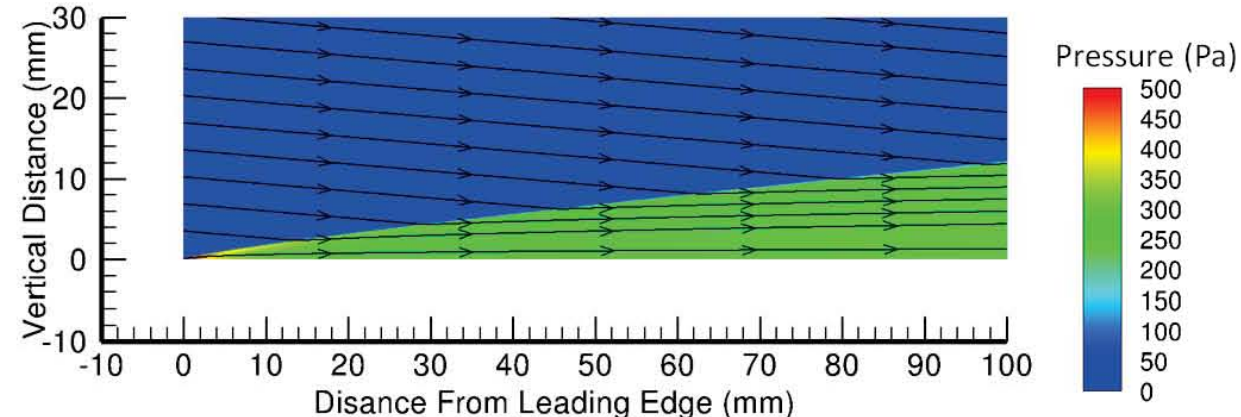

b)
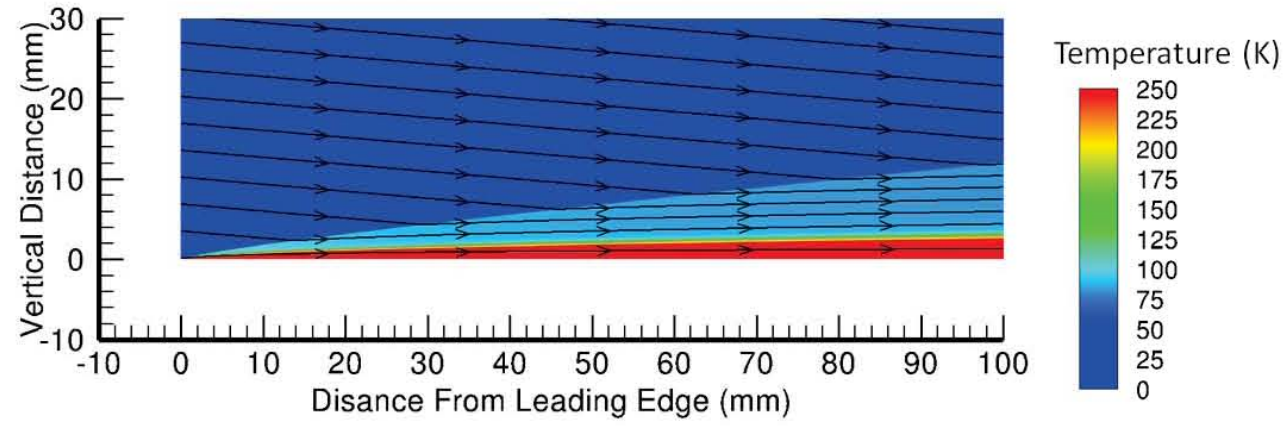

c)

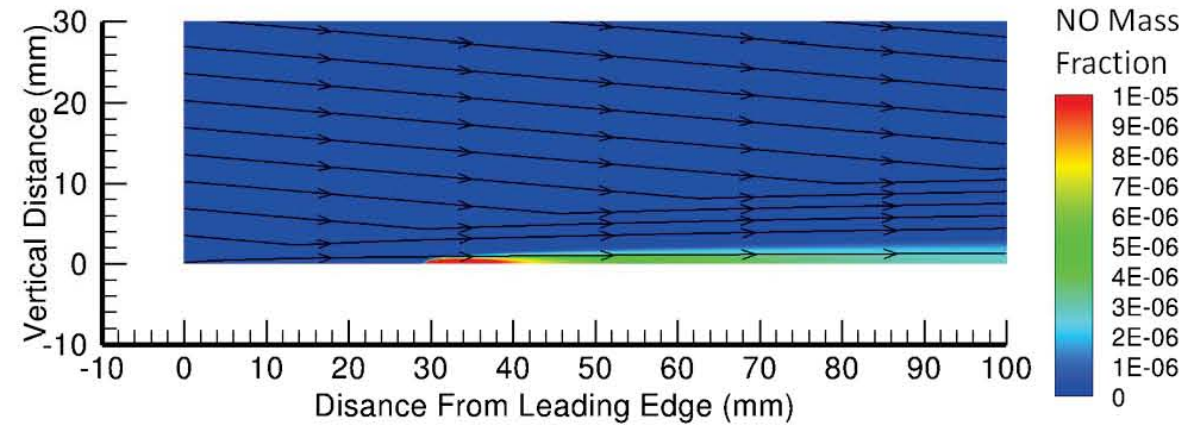

Figure 6: Pressure (a), temperature (b), and concentration (c) fields. Stream traces overlaid to show velocity direction. Diffusion of NO gas from the jet boundary is simulated.

Figure 7 shows the growth of the concentration and velocity boundary layer for cases with $\mathrm{NO}, \mathrm{I}_{2}$, and $\mathrm{Kr}$ diffusive seeding $(0 \mathrm{mg} / \mathrm{s})$. Simulation predictions of the concentration boundary layer growth are compared to theory (Eqn. 1). In the application of Eqn. 1, a Schmidt number of $S c=0.75,0.89$, and 1.35 were used for NO, $\mathrm{Kr}$, and $\mathrm{I}_{2}$ gases, respectively. The velocity and concentration boundary layer thicknesses based on the simulation data were determined through post-processing and defined as the vertical location where $V_{x} / V_{e}=0.99$ and $\left(1-w_{\mathrm{c}}\right) /(1-$ $\left.w_{\mathrm{c}, \max }\right)=0.99$, respectively. The mass fraction of the species of interest is denoted as $w_{\mathrm{c}}$ and the velocity at the edge of the boundary layer is denoted $V_{e}$. A combination of Tecplot macro scripts and C++ was used to post-process the data. The theoretical velocity boundary layer growth was determined from a compressible laminar boundary layer (CLBL) solver available online, which is supported by Virginia Polytechnic Institute and State University (Virginia Tech). ${ }^{26}$ There is good agreement between the simulated and theoretical velocity boundary layer profiles. Small differences are attributed to approximations in the post-shock conditions used for the inputs of the CLBL solver and approximation of fluid properties. In addition, there is good qualitative agreement between the simulation and theory in predicting the trends in the rates of mass diffusion for each gas. For example, the results show that heavier gases diffuse more slowly than the lighter gases. The theory, however, does under-predict the absolute rates of mass diffusion for each of the seeded gases in comparison to the simulation. Since Eqn. 1 is based on incompressible boundary layer assumptions, the theory is not expected to accurately predict the absolute growth rate of the concentration boundary layer. The simulations show that only the NO concentration boundary layer thickness eventually overtakes $(x=85 \mathrm{~mm})$ the velocity boundary layer before the end of the plate. $\mathrm{Kr}$ and $\mathrm{I}_{2}$ remain contained 
within the velocity boundary layer along the entire length of the plate (though $\mathrm{Kr}$ would, and $\mathrm{I}_{2}$ might, eventually approach and exceed the velocity boundary layer edge on a longer plate).

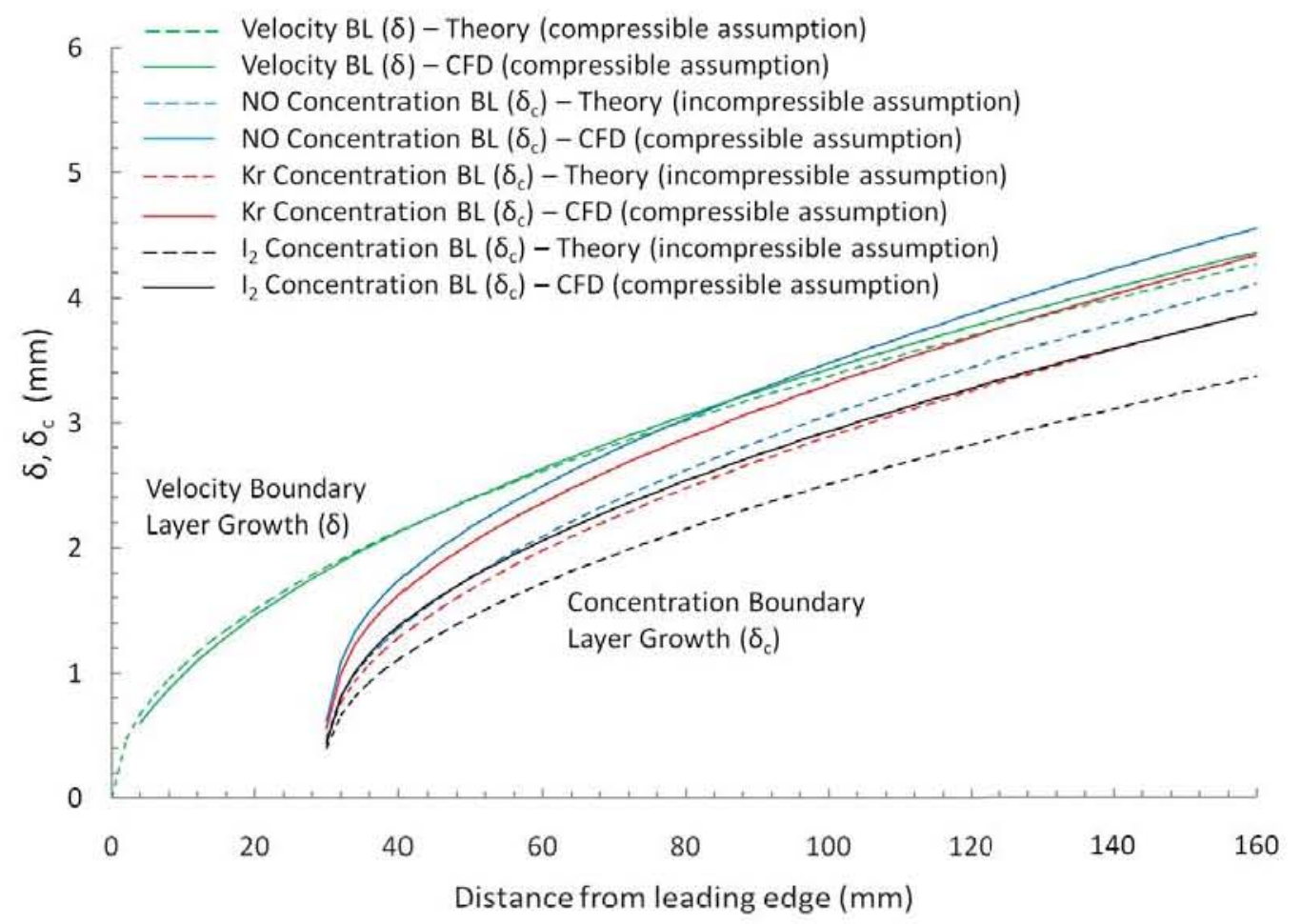

Figure 7: Theoretical and numerical prediction of velocity and concentration boundary layer growth for NO, $\mathrm{Kr}$, and $\mathrm{I}_{2}$ with trace gas seeding (mass flow rate $=0 \mathrm{mg} / \mathrm{s}$ ). Theoretical profiles obtained from Virginia Tech Compressible Laminar Boundary Layer (CLBL) Solver. ${ }^{26}$ Theoretical concentration layer profiles are based on Eqn. 1.

\section{B. Boundary Layer Flow with Jet Gas Seeding}

Figure 8 shows distributions of temperature, pressure, and NO mass fraction from a simulation with gas seeding at a finite mass flow rate. In these simulations, $\mathrm{NO}$ is seeded through the jet inflow boundary at a standard flow rate of 150 standard cubic centimeters per minute $(\mathrm{sccm})$. This flow rate was selected to match the experimental rate used for the majority of PLIF molecular tagging velocimetry (MTV) measurements in previous work. ${ }^{7}$ At standard conditions, this flow rate corresponds to a mass flow rate of approximately $\dot{m}=3 \mathrm{mg} / \mathrm{s}$. A bow shock wave ahead of the jet is visible in the pressure and temperature fields. Although much weaker than the upstream oblique shock wave, the bow shock wave causes a small deflection in the velocity field near the NO jet. Although subtle, both the temperature and velocity boundary layer thicknesses are slightly larger compared to images in Fig. 6. Similar to the diffusive seeding case, NO still remains concentrated near the wall surface (see Fig. 6c) but with concentration levels much larger than that found in the diffusive seeding case. 
a)
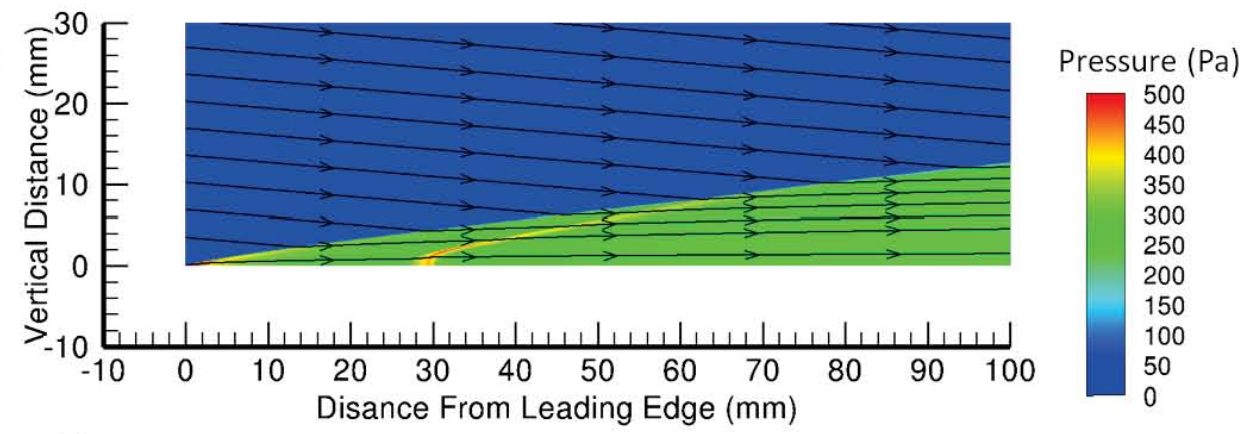

b)

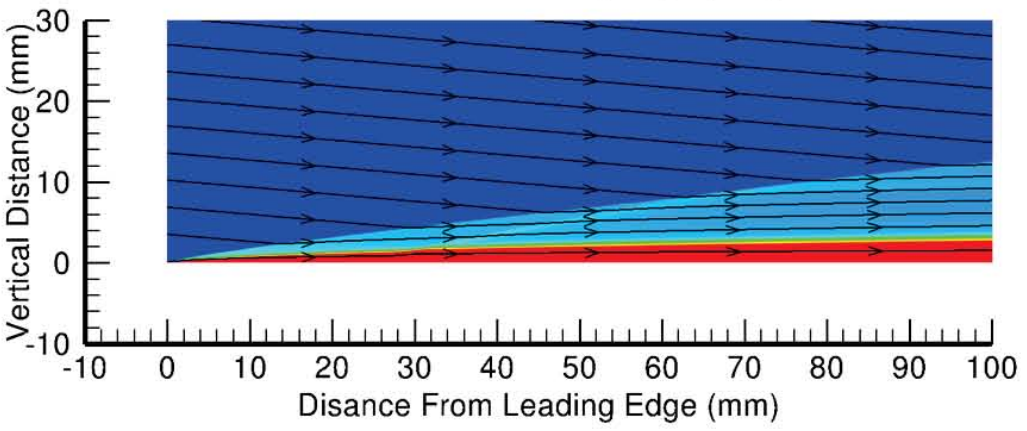

Temperature (K)

c)

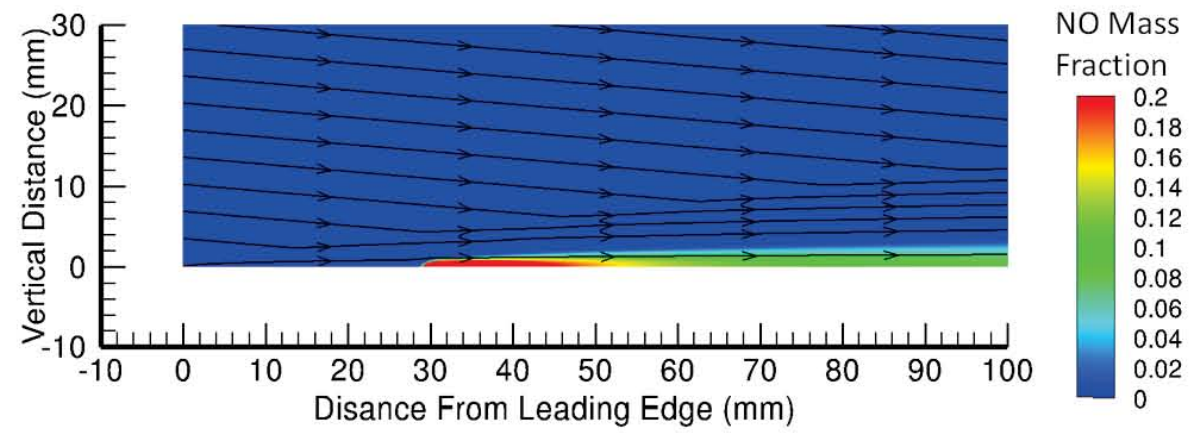

Figure 8: Pressure (a), temperature (b), and concentration (c) fields. Stream traces overlaid to show velocity direction. NO gas seeding flow rate is $150 \mathrm{sccm}$.

Figure 9 shows the effect of the seeded gas mass flow rate on the respective concentration boundary layer thicknesses. The results indicate that increasing the mass flow rate from $\dot{m}=0 \mathrm{mg} / \mathrm{s}$ to $\dot{m}=0.3 \mathrm{mg} / \mathrm{s} \mathrm{has} \mathrm{a}$ negligible impact on the concentration boundary layer thickness. An increase to $\dot{m}=3 \mathrm{mg} / \mathrm{s}$, however, causes a noticeable increase in the thickness for each case simulated. For example, at $x=106 \mathrm{~mm}$, the increases in concentration boundary layer thicknesses are $3.6 \%, 4.8 \%$, and $2.9 \%$ for $\mathrm{NO}, \mathrm{Kr}$, and $\mathrm{I}_{2}$ seeded gases, respectively. In addition to the diffusion of mass, the finite momentum of the seeded gas allows convection deeper into the velocity boundary layer. The original velocity boundary layer has been included in the figure as a reference. To avoid clutter in the figure, the corresponding velocity boundary layer profiles have not been included, and are instead shown in the following figure. 


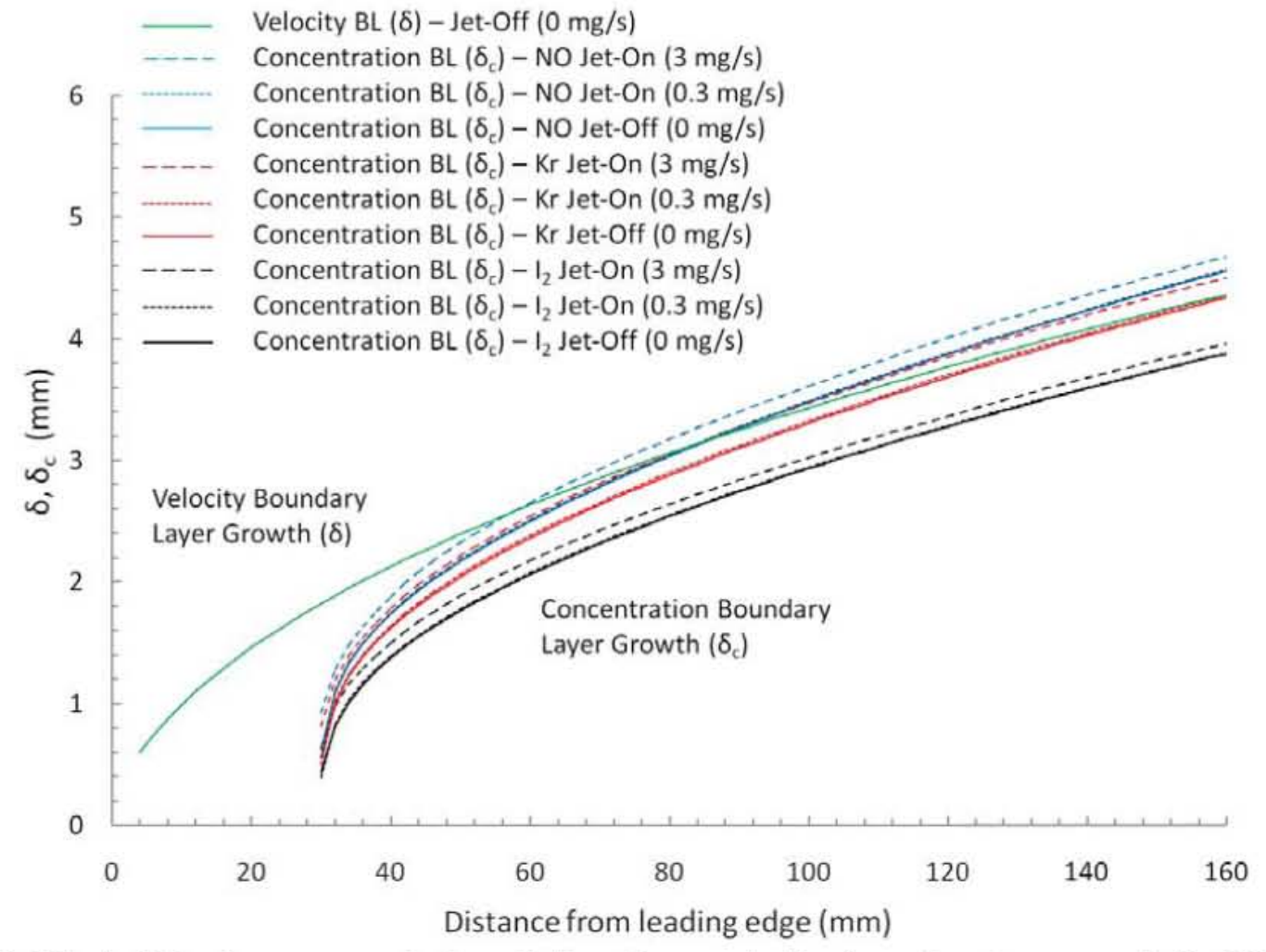

Figure 9: Effect of blowing on numerical prediction of concentration boundary layer growth for $\mathrm{NO}$, $\mathrm{Kr}$, and $\mathbf{I}_{2}$.

Figure 10 shows the influence of the gas seeding on the velocity boundary layer thickness profiles. In these profiles, the corresponding mass flow injection rates of $\mathrm{NO}, \mathrm{Kr}$, and $\mathrm{I}_{2}$ were $\dot{m}=3 \mathrm{mg} / \mathrm{s}$. The results indicate that the injection of NO causes a slightly larger deflection in the velocity field than the other gases. Since the mass flow rate is equivalent in each case, a large difference between the predicted magnitudes of deflection is not expected. Although each seeded gas is able to convect further from the wall because of higher seeding flow rates, the streamwise location at which the concentration boundary layer intersects with the velocity boundary layer actually increases because of the increased thickness of the boundary layer. For example, the streamwise distance of this intersection for NO seeding increases from $85 \mathrm{~mm}$ (Fig. 9) to $100 \mathrm{~mm}$ (Fig. 10) when the jet mass flow rate is increases from $\dot{m}=0 \mathrm{mg} / \mathrm{s}$ to $\dot{m}=3 \mathrm{mg} / \mathrm{s}$. In both $\mathrm{Kr}$ seeding cases, the concentration layer thickness approaches the velocity boundary layer thickness near the end of the figure $(x=160 \mathrm{~mm})$. Herein only cases with a corresponding jet mass flow rate of $\dot{m}=3 \mathrm{mg} / \mathrm{s}$ will be analyzed. Experimentally, this minimum flow rate was required to achieve acceptable PLIF signal levels (NO gas seeding). ${ }^{7}$ 


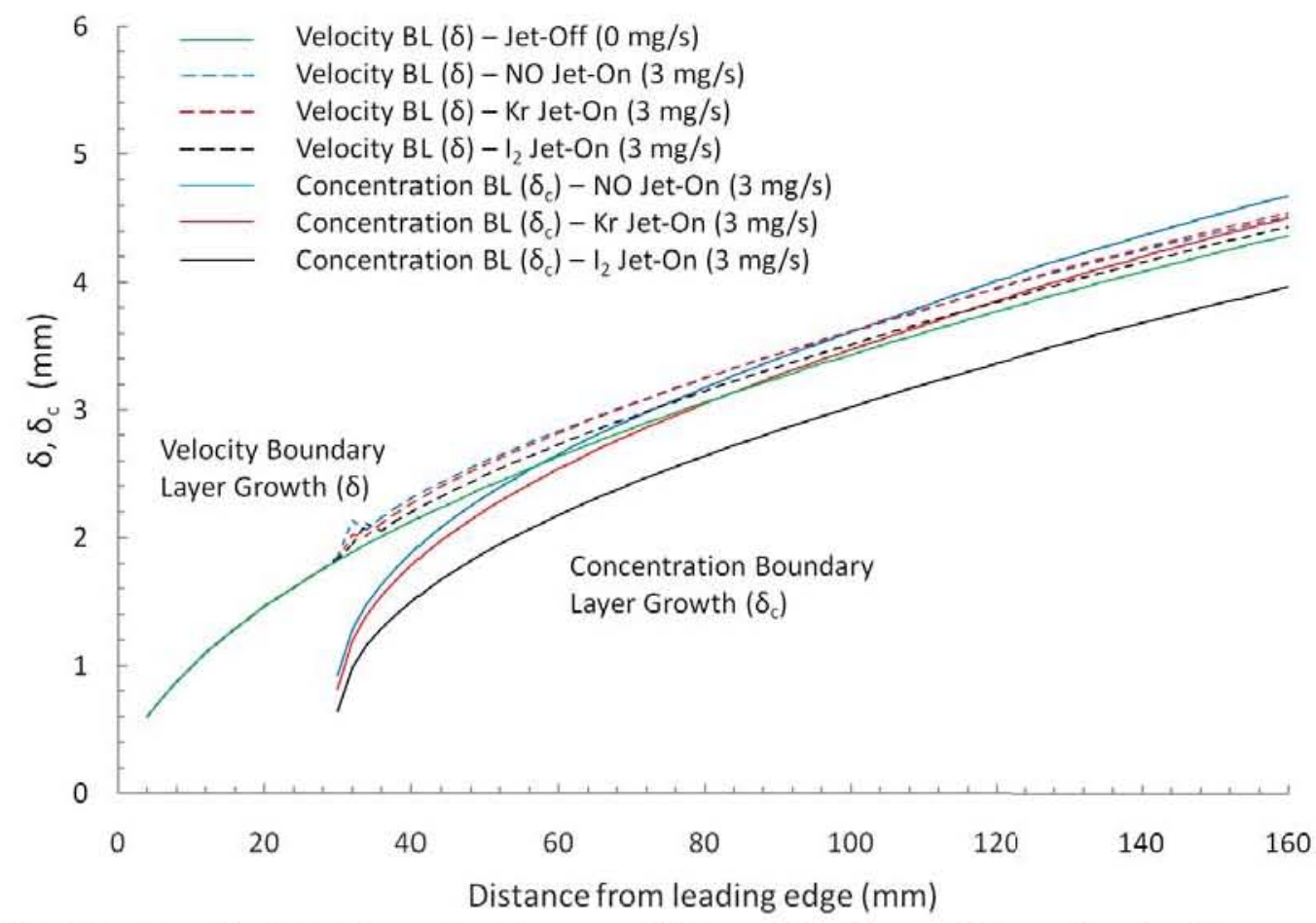

Figure 10: Deflection of velocity boundary layer profile from $\mathrm{NO}, \mathrm{Kr}$, and $\mathrm{I}_{2}$ seeding. Seeding mass flow rate is $\dot{m}=3 \mathrm{mg} / \mathrm{s}$.

The initial deflections of the velocity boundary layer thickness profile for the $\mathrm{NO}$ and $\mathrm{Kr}$ seeding cases occur further upstream compared to the deflection associated with the $I_{2}$ seeding case. Deflections occurring further upstream are caused by higher jet velocities associated with the seeded gas. Figure 11 shows contour maps of the species mass fraction with velocity stream traces overlaid for each respective seeded gas near each jet inflow boundary. The scale in the vertical direction has been expanded to help illustrate the adverse effects that the gas seeding has on the velocity field. Since $\mathrm{NO}$ has a lower molecular mass than both $\mathrm{Kr}$ and $\mathrm{I}_{2}$, the jet velocity increases to satisfy the conservation of mass. 
a)

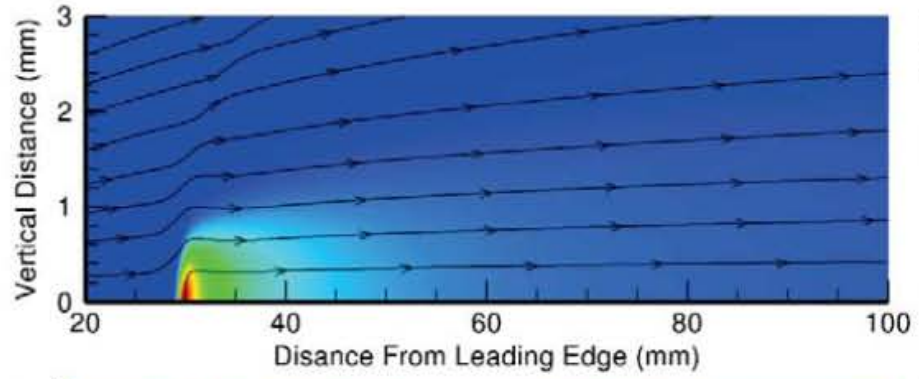

b)

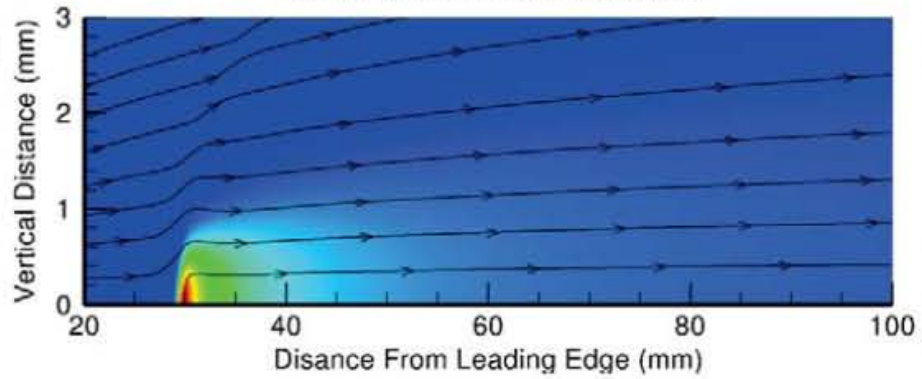

c)

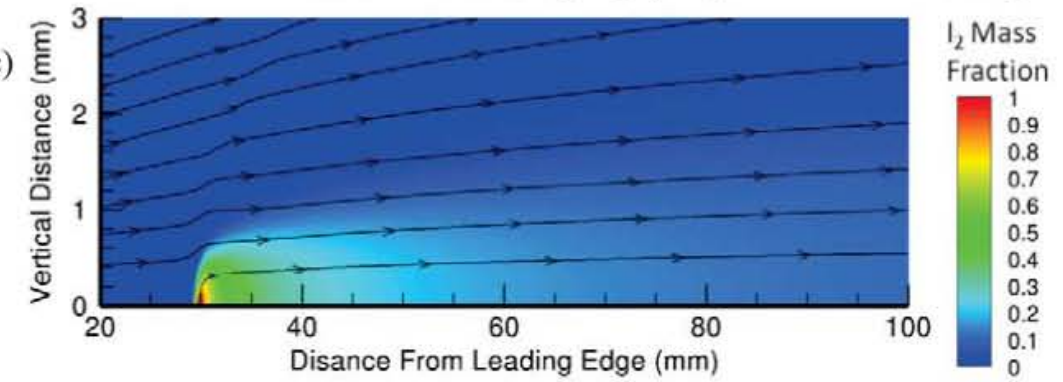

NO Mass

Fraction

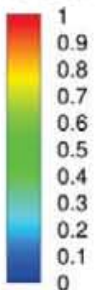

KrMass

Fraction

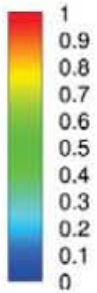

0.9

0.8

0.6

0.4

7
6
5
4
3
2
1

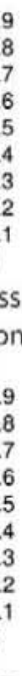
6

Figure 11: Deflection of velocity field from $\mathrm{NO}$ (a), $\mathrm{Kr}(\mathrm{b})$ and $\mathrm{I}_{2}$ (c) gas seeding. Stream traces overlaid to show velocity direction. Gases are injected at a mass flow rate of $\dot{m}=\mathbf{3 m g} / \mathrm{s}$, which is equivalent to an NO flow rate of $150 \mathrm{sccm}$. Scale is expanded in vertical direction to assist in illustrating deflection effect.

Although the analysis of the concentration boundary layer thickness is useful for understanding the maximum extents that each seeded gas will advect and diffuse in the vertical direction, it is also important to analyze the vertical distributions of mass distribution for each case. Figure 12 shows distributions of velocity, temperature, and species mass fraction for cases with $\mathrm{NO}, \mathrm{Kr}$, and $\mathrm{I}_{2}$ seeded gases $(\dot{m}=3 \mathrm{mg} / \mathrm{s})$. These profiles are compared to a jetoff case, where gas is not injected through the jet-inflow boundary. These profiles are located $106 \mathrm{~mm}$ downstream of the plate's leading edge. Similar to observations from the effect of gas seeding on the velocity boundary layer thickness predictions, the velocity and temperature fields are slightly affected by the seeding process ( $\dot{m}=3 \mathrm{mg} / \mathrm{s})$.

The distribution of $\mathrm{l}_{2}$ compared to both $\mathrm{NO}$ and $\mathrm{Kr}$ has implications for any potential PLIF signal that could be measured near the edge of the velocity boundary layer. $\mathrm{I}_{2}$ remains more concentrated near the wall boundary, which suggests that PLIF signals for $\mathrm{I}_{2}$ seeding would be lower than PLIF signals with $\mathrm{NO}$ or $\mathrm{Kr}$ seeding near the edge of the velocity boundary layer (assuming the same mass flow rate). At this streamwise position the thermal boundary layer based on the temperature profile is approximately $15 \%$ thicker than the velocity boundary layer. As a result, an NO PLIF signal can be obtained across the full velocity boundary layer, but will not be available at the outer edges of the temperature boundary layer. At the end of the computation domain $(x=200 \mathrm{~mm})$, the NO concentration layer was still smaller than the temperature boundary layer. The vertical distribution of mass associated with each seeded gas is affected by the distribution of local Schmidt numbers. As the seeded gas mixes with the crossflow, changes in temperature and mixture composition affect levels of viscosity, density, and mass diffusion rates. Figure 13 shows a vertical Schmidt number distribution for each seeding gas along with a vertical distribution of normalized species mass fraction $106 \mathrm{~mm}$ downstream of the leading edge. As expected, with higher Schmidt numbers the gas is unable to penetrate far into the boundary layer. 


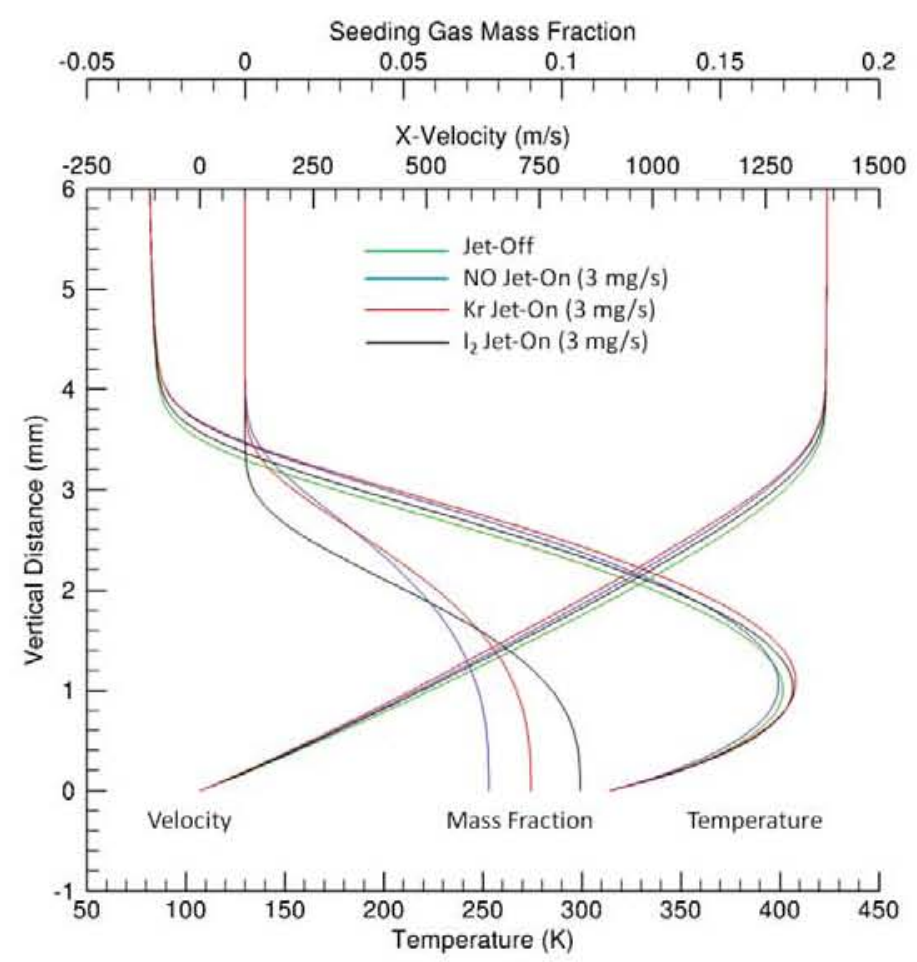

Figure 12: Distributions of velocity, species, and temperature for $\mathrm{NO}, \mathrm{Kr}$, and $\mathbf{I}_{2}$ gas seeding techniques. Gases are injected at a mass flow rate of $3 \mathrm{mg} / \mathrm{s}$. Profiles located $106 \mathrm{~mm}$ downstream of leading edge.

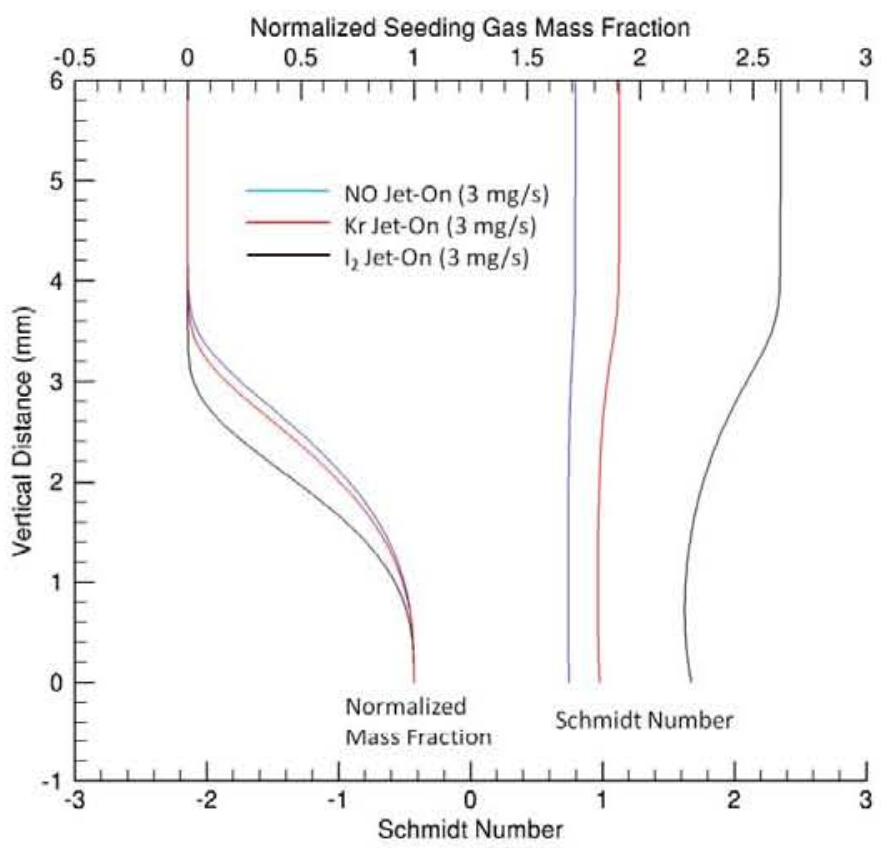

Figure 13: Schmidt number and mass diffusion of gas. Gases are injected at a mass flow rate of $3 \mathrm{mg} / \mathrm{s}$. Profiles located $106 \mathrm{~mm}$ downstream of leading edge.

Interestingly, the difference in the Schmidt number between each seeded gas is lower near the wall surface than at the edge of the velocity boundary layer. As a result, the diffusion rate of $\mathrm{I}_{2}$ relative to $\mathrm{NO}$ is much lower at the 
edge of the velocity boundary layer. This causes $I_{2}$ to remain more concentrated near the wall surface whereas NO and $\mathrm{Kr}$ concentrations become more distributed with downstream distance. Note that the difference in Schmidt number between each seeded gas only varies by a factor of two, despite the much larger variation in molecular weight (factor of 10). To further understand the distributions of the Schmidt number, Fig. 14 shows the breakdown in thermodynamic quantities that contribute to the dimensionless number (Eqn. 2). Since the mass fraction of the seeded gas is low at this streamwise location, the local density and viscosity are not largely affected by the jet composition. Near the wall surface, viscous heating causes the gas temperature to rise, which acts to both decrease the local gas density and increase the local dynamic viscosity. This combination alone would result in an increase in the Schmidt number, which would inhibit the growth of the concentration boundary layer relative to the velocity boundary layer. The local diffusion coefficient for each gas, however, is dependent on the jet composition and gas temperature. Based on kinetic theory, a rise in gas temperature is accompanied with a corresponding rise in the binary diffusion coefficient. The total combination of these changes in thermodynamic properties causes the Schmidt number to decrease near the wall surface, promoting growth of the concentration boundary layer relative to the velocity boundary layer.

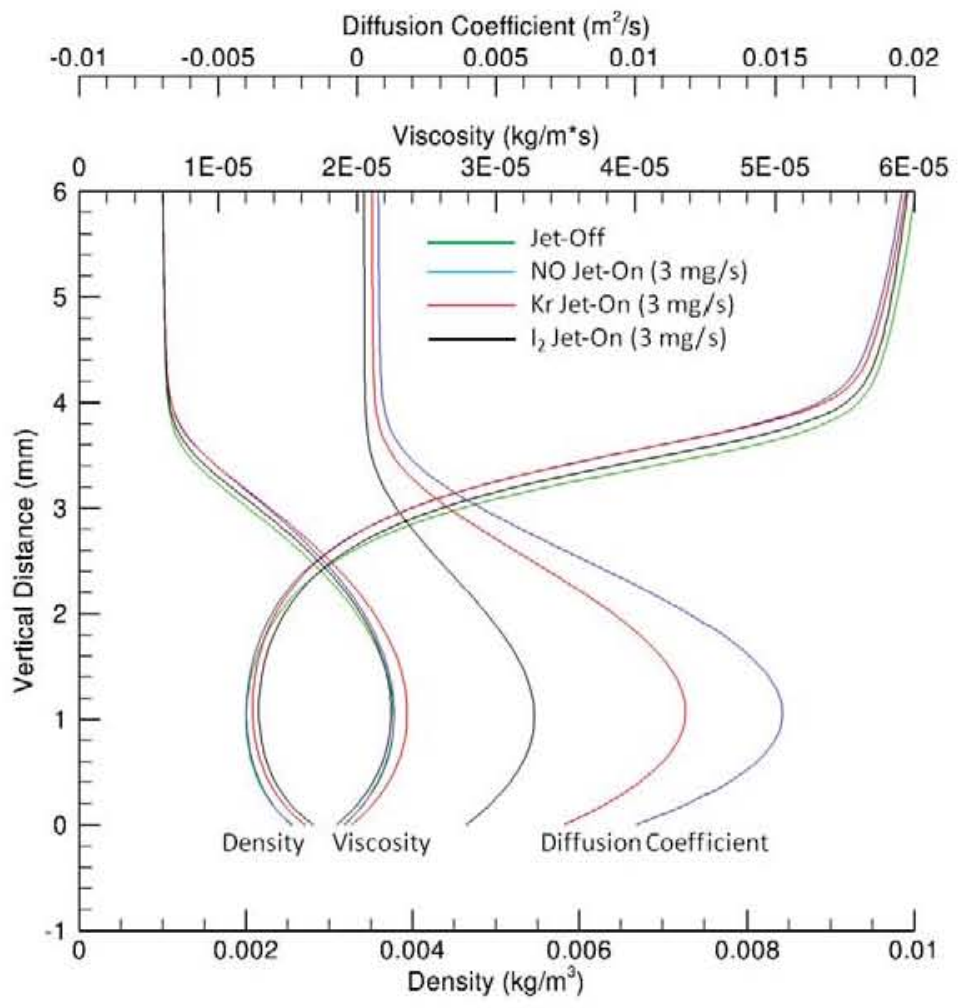

Figure 14: Components of the gas Schmidt number. Gases are injected at a mass flow rate of $\dot{m}=\mathbf{3} \mathrm{mg} / \mathrm{s}$. Profiles located $106 \mathrm{~mm}$ downstream of leading edge.

\section{Discussion}

In a previous NO PLIF MTV experiment that studied the transition to turbulence in a hypersonic boundary layer, good signal-to-noise levels were achieved with an NO seeding flow rate of $150 \mathrm{sccm}(\dot{m}=3 \mathrm{mg} / \mathrm{s}){ }^{7}$. The model geometry, test conditions, and plate angle were equivalent to those described in the current study. Experimentally, reducing the flow rate by a factor of 10 in order minimally perturb the flow, as indicated by the CFD results of this work, would result in insufficient PLIF signal levels with the current experimental setup. The flow rate could be reduced if changes were made to either the laser excitation or the detection system. Obvious improvements to the excitation system include a more powerful laser source (though saturation of the fluorescence transition can limit the laser energy used), exciting a stronger transition, or broadening the linewidth of the laser to excite more of the molecules in the Doppler-broadened Voigt profile. The detection system could be improved by using a larger UV 
lens to collect more light or using an intensified CCD camera with a higher quantum efficiency or a more efficient coupling between the intensifier and the CCD.

\section{Future Work}

Since the motivation of this study is to compare various gas seeding strategies, the relationship between the LIF signal and species concentration should also be considered. Because comparisons were made on a mass flow rate basis, fewer $\mathrm{Kr}$ and $\mathrm{I}_{2}$ molecules are injected into the flow compared to NO. It is therefore likely that the total LIF signals from $\mathrm{Kr}$ and $\mathrm{I}_{2}$ seeding would also be lower than the total LIF signal obtained from NO seeding since many more NO molecules would be present than the heavier molecules, on a mass flow rate basis. The LIF signal, however, is not only dependent on the concentration of the fluorescence species, but also on other parameters including collisional quenching, which affects the fluorescence yield, and laser saturation. Because quantifying the LIF signal for each species was out of the scope for this paper, comparisons were based on a constant jet mass flow rate. By using fluorescence models to predict the LIF signal based on the thermodynamic properties of the flow, a better comparison between seeding techniques would be obtained. Another consideration ignored in this comparison is the practicality of seeding pure $\mathrm{I}_{2}$ into a flow. The vapor pressure of $\mathrm{I}_{2}$ is only $50 \mathrm{~Pa}$ at room temperature. In order to flow pure $I_{2}$ into a flow at $300 \mathrm{~Pa}$, as computed above, a heated source of $\mathrm{I}_{2}$ would be required. Furthermore, the delivery lines and the internal plumbing of the wind tunnel model would need to be heated to 325 $\mathrm{K}$ or higher to avoid $\mathrm{I}_{2}$ condensation at this pressure - an added experimental complication.

Additional flow physics should be added and studied in future work. For example, the influence of the plate angle has a large effect on the post-shock conditions, which changes the interaction between the jet and crossflow. The simulation of $\mathrm{NO}_{2}$ seeding, which is used for $\mathrm{NO}$ flow-tagging by photo-dissociation of $\mathrm{NO}_{2}$, is also of interest. Furthermore, possible reactions between $\mathrm{NO}$ and $\mathrm{O}_{2}$ deposit heat into the flow and depletes the concentration of the fluorescent species. Unsteadiness in the seeding might also cause or amplify instability modes in the flow that could lead to the transition to turbulence. Extension of the computational domain into three dimensions in addition to modeling the internal gas seeding geometry would be required to study this phenomenon.

\section{Conclusions}

Numerical simulations comparing gas seeding techniques used for PLIF measurements in a hypersonic boundary layer on a flat plate have been performed. Predictions of the velocity boundary layer thickness agree well with the Virginia Tech's CLBL code. Although based on incompressible assumptions, the analytical expression (Eqn. 1) agrees with the numerical predictions of the relative concentration boundary layer growth for each seeded gas. It was found that increasing the seeded gas jet mass flow rate results in an increase in species concentration but does not increase the growth rate of the concentration boundary layer relative to the velocity boundary layer. For a fixed jet mass flow rate of $\dot{m}=3 \mathrm{mg} / \mathrm{s}$, each of the species investigated $\left(\mathrm{NO}, \mathrm{Kr}\right.$, and $\mathrm{I}_{2}$ ) perturbed the velocity boundary layer ( $I_{2}$ the least and NO the most). Further analysis of the local distribution of the Schmidt number showed why $I_{2}$ remains concentrated near the wall surface while $\mathrm{NO}$ and $\mathrm{Kr}$ become more distributed towards the edge of the velocity boundary layer. For the jet flow rates simulated, NO is the only seeded gas to penetrate beyond the edge of the velocity boundary layer (though not the thermal boundary layer) before reaching the end of the plate. This is an important result because transition from laminar to turbulent flow has been reported to occur at the edge of the boundary layer in hypersonic flows. ${ }^{13}$ Although much heavier than $\mathrm{NO}$, both $\mathrm{Kr}$ and $\mathrm{I}_{2}$ were found to diffuse far into the velocity boundary layer allowing PLIF to be used with these seeding techniques, albeit closer to the wall than for NO.

\section{Acknowledgements}

Dr. Johansen was supported by the Natural Sciences and Engineering Research Council of Canada (NSERC). This work was supported by the NASA Fundamental Aeronautics Program, Hypersonics Project, AerodynamicsAerothermodynamics-Plasma (AAP) Discipline.

\section{References}

1 J.S. Fox, A.F.P. Houwing, P.M. Danehy, M.J. Gaston, N.R. Mudford, S.L. Gai, "Mole-Fraction-Sensitive Imaging of Hypermixing Shear Layers," Journal of Propulsion and Power, 17(2), p. 284-292, (2001). 
2 J.A. Inman, P.M. Danehy, D.W. Alderfer, and G.M. Buck, and A. McCrea, "Planar Fluorescence Imaging and Three Dimensional Reconstructions of Capsule Reaction-Control-System Jets", AIAA Journal, Vol. 47, No. 4, April (2009).

${ }^{3}$ P.M. Danehy, J.A. Inman, G. Brauckmann, D.W. Alderfer, S.B. Jones, and D. Patry, "Visualization of a capsule entry vehicle reaction-control-system thruster," Journal of Spacecraft and Rockets, Vol. 46, No. 1, pp. 93$102,2009$.

${ }^{4}$ N. Jiang, M. Webster, W.R. Lempert, J.D. Miller, T.R. Meyer, C.B. Ivey, and P.M. Danehy, "MHz-rate nitric oxide planar laser-induced fluorescence imaging in a Mach 10 hypersonic wind tunnel," Applied Optics, Vol. 50, No. 4, Feb (2011).

${ }^{5}$ T. Medford, P.M. Danehy, S.B. Jones, B.F. Bathel, J.A. Inman, N. Jiang, M. Webster, W. Lempert, J. Miller, and T. Meyer, "Stereoscopic planar laser-induced fluorescence imaging at $500 \mathrm{kHz}$ " Paper AIAA 2011-985, 49 AIAA Aerospace Sciences Meeting including the New Horizons Forum and Aerospace Exposition, Orlando, Florida, Jan. 4-7, 2011.

${ }^{6}$ P.M. Danehy, C.B. Ivey, J.A. Inman, B. Bathel, S.B. Jones, A.C. McCrea, N. Jiang, M. Webster, W. Lempert, J. Miller, and T. Meyer, "High-speed PLIF imaging of hypersonic transition over discrete cylindrical roughness," Paper AIAA-2010-0703, 48 'h AIAA Aerospace Sciences Meeting, Fluid Dynamics TC, Orlando Florida, Jan 2010.

${ }^{7}$ B.F. Bathel, P.M. Danehy, J.A. Inman, S.B. Jones, C.B. Ivey, and C.P. Goyne, "Multiple velocity profile measurements in hypersonic flows using sequentially-imaged fluorescence tagging," AIAA Journai, Vol. 49, No. 9, 2011,pp. 1883- 1896.

${ }^{8}$ B.F. Bathel, P.M. Danehy, J.A. Inman, A.N. Watkins, S.B. Jones, W.E. Lipford, K.Z. Goodman, C.B. Ivey, C.P. Goyne, "Hypersonic laminar boundary layer velocimetry with discrete roughness on a flat plate," Paper AIAA 2010 4998, 40 ${ }^{\text {th }}$ AIAA Fluid Dynamics Conference and Exhibit, Chicago IL, June 2010.

${ }^{9}$ B.F. Bathel, P.M. Danehy, J.A. Inman, S.B. Jones, C.B. Ivey, and C.P. Goyne, "Multiple velocity profile measurements in hypersonic flows using sequentially-imaged fluorescence tagging," Paper AIAA 2010-1404, 48 ${ }^{\text {th }}$ AIAA Aerospace Sciences Meeting, AMT TC, Orlando FA, Jan. 2010.

${ }^{10}$ T.J. Horvath, S. A. Berry, N.R. Merski, K. T. Berger, G.M. Buck, D.S. Liechty, and S.P. Schneider, "Shuttle damage/repair from the perspective of hypersonic boundary layer transition - experimental results" AIAA 20062919, the $9^{\text {th }}$ AIAA/ASME Joint Thermophysics and Heat Transfer Conference, San Francisco, CA, June 2006.

${ }^{\prime \prime}$ P.M. Danehy, C.B. Ivey, B.F. Bathel, J.A. Inman, S.B. Jones, A.N. Watkins, K.Z. Goodman, A.C. McCrea, B.D. Leighty, W.K. Lipford, N. Jiang, M. Webster, W. Lempert, J. Miller, and T. Meyer "Orbiter BLT flight experiment wind tunnel simulations: nearfield flow imaging and surface thermography", AIAA Paper 2010-1571 $48^{\text {th }}$ AIAA Aerospace Sciences Meeting, Orlando, FA, Jan 2010.

${ }^{12}$ B.F. Bathel, P.M. Danehy, J.A. Inman, D.W. Alderfer, and S.A. Berry, "PLIF Visualization of Active Control of Hypersonic Boundary Layers Using Blowing," AIAA-2008-4266. 26 ${ }^{\text {th }}$ AIAA Aerodynamic Measurement Technology and Ground Testing Conference, Seattle, WA, June 23-26, 2008.

${ }^{13}$ M.C. Fischer, "Spreading of a Turbulent Disturbance," AIAA Journal, vol.10 no.7 p. 957-959, 1972.

${ }^{14}$ K. Asano, Mass Transfer: From Fundamentals to Modern Industrial Applications, WILEY-VCH Verlag GMbH \& Co. KGaA, Weinheim, SBN 3-527-31450-1, 2006.

${ }^{15}$ Narayanaswamy, V., Burns, R. J., and Clemens, N.T., "Two-dimensional imaging of an under-expanded jet using two photon LIF of Krypton", Optics Letters, Vol. 36, Issue 21, pp. 4185-4187 (2011).

${ }^{16}$ R. J. Hartfield, Jr., J. D. Abbitt III, and J. C. McDaniel, "Injectant mole-fraction imaging in compressible mixing flows using planar laser-induced iodine fluorescence," Optics Letters, Vol. 14, Issue 16, pp. 850-852 (1989)

17 R. J. Exton, R. J. Balla, B. Shirinzadeh, M. E. Hillard and G. J. Brauckmann, "Flow visualization using fluorescence from locally seeded I2 excited by an ArF excimer laser," Experiments in Fluids, Vol. 26, No. 4, 335339,1999

${ }^{18}$ Occupational Safety \& Health Administration, US Department of Labor, http://www.osha.gov/web/dep/chemicaldata/default.asp accessed December 8, 2011.

${ }^{19}$ J.M. Weiss, J.P. Maruszewski, and W.A. Smith, "Implicit solution of the Navier-Stokes equations on unstructured meshes," AIAA-97-2103, 13 ${ }^{\text {th }}$ AIAA CFD Conference, Snowmass, CO, July 1997.

${ }^{20}$ P.L. Roe, "Characteristic based schemes for the Euler equations," Annual Review of Fluid Mechanics, Vol 18 , pp. 337-365, 1986.

${ }^{21}$ Hollis, "Real-gas flow properties of NASA Langley Research Center aerothermodynamics facilities complex wind tunnels" NASA Contractor Report 4755, 1996.

${ }^{22}$ NIST-JANAF Thermochemical Tables, http://kinetics.nist.gov/janaf/, accessed May 19, 2011. 
${ }^{23}$ R.A. Svehla, "Estimated viscosities and thermal conductivities of gases at high temperatures" NASA Technical Report R-132, 1962.

${ }^{24}$ R.S. Brodkey and H.C. Hershey, Transport Phenomena, A Unified Approach, McGraw-Hill Chemical Engineering Series, 1988.

${ }^{25}$ P.D. Neufeld, A.R. Janzen, and R.A. Aziz, "Empirical equations to calculate 16 of the transport collision integrals for the Lennard-Jones (12-6) potential" Journal of Chemical Physics, Vol. 57, Issue 3, pp. 1100-1102, 1972.

${ }^{26}$ W.J. Devenport, Boundary Layer Applets, http://www.engapplets.vt.edu/fluids/bls2, accessed May 19, 2011. 